\title{
Entre palavras e
}

imagens. Onde fica

mesmo o índio na

fundação do Brasil?

Uma discussão a partir

dos filmes: Palavra e

\section{utopia (2000) e Anchieta, \\ José do Brasil (1977)}

\begin{abstract}
Maria Ignês Carlos Magno
Doutora em Ciências da Comunicação pela ECA-USP. Professora do mestrado em Comunicação da Universidade Anhembi Morumbi e da Fundação Escola de Sociologia e Política de São Paulo.

E-mail: unsigster@gmail.com
\end{abstract}

Resumo: A proposta dessa resenha é discutir a partir dos filmes Palavra e utopia, do cineasta Manoel de Oliveira, e Anchieta, José do Brasil, de Paulo César Saraceni, as complexas relações entre os colonizadores e os indígenas do Brasil. Tendo a palavra como o elemento central das reflexões, pensei em dois filmes que mostram através das imagens a força da palavra e a ambiguidade dos sentimentos dos colonizadores em relação ao Brasil e aos aborígines. A proposta aqui não é abordar os textos e os filmes sob a ótica do afeto, mas da ambiguidade contidas nos afetos e nos discursos dos padres José de Anchieta e Antonio Vieira.

Palavras-chave: cinema; comunicação; educação; colonização.
Abstract: The purpose of this review is to discuss, from the movies Word and Utopia, by the filmmaker Manoel de Oliveira and Anchieta, José do Brazil, by Paulo Cesar Saraceni, the complex relationships between the colonizers and Brazilian natives. Having the word as the key element of reflection, I thought about two Imovies showing through images the power of words and the ambiguity of the feelings of the colonizers in relation to Brazil and the indigenous. The purpose here is not to approach the texts and movies from the perspective of affection, but the ambiguity contained in the affections and in the discourses of priests José de Anchieta and Antonio Vieira.

Keywords: cinema; communication; education; colonization. 
comunicação \& educação • Ano XX • número 2 • jul/dez 2015

\section{INTRODUÇÃO}

O mês de julho no nosso hemisfério sul é dedicado, entre tantas festividades, às férias escolares. E como gostamos desse mês! Todos, alunos e professores. É tempo de viajar, de passear, de não fazer nada. Tempo de organizar os papéis e os livros que se acumularam sobre as mesas ao longo do semestre. E nesse tempo, entre limpar, folhear e reordenar os livros nas estantes da biblioteca, notamos que é também um tempo de surpresas, de descobertas e redescobertas. Os livros estão todos lá à espera de serem relidos pela décima vez ou lidos pela primeira vez. Se observarmos os movimentos de nossos olhos e mãos, percebemos que são eles, os livros, que nos escolhem. Nesse movimento, uma descoberta ocasional e em seguida uma redescoberta. A descoberta foi a de um livro chamado Saudade. O percurso de um sentimento ambíguo, de Samuel de Jesus $^{1}$, e a redescoberta foi a do livro Sermões, do Padre Antonio Vieira. Melhor dizendo, o livro Saudade me levou aos Sermões e os dois me levaram aos filmes: Palavra e utopia (2000), de Manuel de Oliveira, e Anchieta, José do Brasil (1977), de Paulo César Saraceni. Como a palavra é o elemento central das reflexões dos autores nos livros, pensei, para essa resenha, em dois filmes que mostram por meio das imagens a força da palavra e a ambiguidade dos sentimentos dos colonizadores em relação ao Brasil e aos aborígines.

O autor de Saudade inicia seu livro descrevendo a sala de leitura de uma biblioteca, as prateleiras, a perfeita simetria do lugar dando conta de toda amplidão do lugar, a estilística da ornamentação, o espaço central da sala mobiliada apenas com mesas de leitura no "seio da qual reina o vazio e o silêncio absolutos" ${ }^{2}$. Descrição necessária para que o leitor entenda o enigma que se propõe decifrar ao longo de seu estudo, porque no "meio dessa preciosa coleção de obras, muitas vezes raras, conservadas com grande cuidado, encontra-se o que serviu de ponto de partida para este estudo"'s: uma fotografia. A fotografia do Real Gabinete Português de Leitura, instituição fundada em 1837 por um grupo de 43 emigrantes portugueses, tendo sido um deles Marcelino Rocha Cabral, seu primeiro presidente ${ }^{4}$. Entre o impacto causado pela imagem fotográfica aos estudos da palavra saudade, e as perguntas que o autor faz sobre a força evocatória dessa palavra considerada a expressão literária e artística maior da cultura lusófona e transformada num sentimento universal, podemos entender por que ela continua a ressoar ainda hoje em todos os países ligados a um longo passado colonial português, do Brasil ao Cabo Verde, e porque permanece até nossos dias "uma das chaves indispensáveis para a compreensão das culturas lusófonas através do mundo, tendo sua herança permanecido profundamente ancorada nas diferentes camadas culturais e sociais portuguesas e brasileiras, principalmente desde as primeiras expedições marítimas" ${ }^{5}$. A força dessa palavra pode ser apreendida logo na apresentação do livro feita pelo professor Joaci Pereira Furtado, que a inicia com a seguinte citação: “'Onde o ausente é comida, as saudades são fome', escreve Antonio Vieira no Índice das coisas mais notáveis. Parece dizer bem o 'imperador da língua portuguesa' (como o 
nomeou Fernando Pessoa), essa mesma língua que se orgulha de ter uma única palavra para designar um sentimento cuja ambiguidade parece intraduzivel aos outros idiomas - e, portanto, às outras culturas". [...]. Samuel de Jesus, continua o professor Joaci, "empreende exaustivo estudo sobre as relações entre aquela invenção relativamente recente, hoje tão universal e popularizada, e esse afeto no âmbito da cultura luso-brasileira”. Era a segunda vez em menos de um mês que eu lia a mesma frase e a mesma referência de Pessoa a Antonio Vieira como "imperador da língua portuguesa". A partir dessas colocações fui aos textos de Antonio Vieira, em especial o Sermão da Epifania, pregado na Capela Real, em 1662, em defesa dos índios contra os colonos do Maranhão. Além do vínculo afetivo, que a despeito de nossas diferenças, sentimos, dois fatos vieram à mente: a colonização portuguesa e a força impositiva da língua nos lugares onde se instalaram. Particularmente, duas personagens que tanta influência tiveram sobre nós, e especialmente sobre os índios: os padres José de Anchieta e Antonio Vieira. A partir das descobertas e redescobertas literárias, pensei nos dois filmes que tratam da vida desses jesuítas no Brasil. No entanto, a proposta aqui é abordar os textos e os filmes não sob a ótica da saudade e do afeto, mas da ambiguidade contidas nesses afetos.

\section{OS FILMES E A HISTÓRIA}

O filme Anchieta, José do Brasil (1977), de Paulo Cesar Saraceni, narra a vida de José de Anchieta entre os índios brasileiros, desde 1553, ano de sua chegada ao Brasil, até 1597, ano de sua morte. Ao crescer, vai para Coimbra cursar a faculdade e torna-se um homem estudioso e religioso. A Companhia de Jesus o envia para o Brasil, onde o Governador Geral inicia a tentativa de escravizar os índios, que, valentes, tentam resistir. Chegando ao Brasil em 1553, José de Anchieta, em apenas três meses de contato com os nativos, aprende a língua dos índios tupi e a registra em uma gramática. Com obstinada paixão, estuda os hábitos e costumes dos índios, classifica plantas e frutas locais. Interfere no conflito entre indígenas e colonos europeus, evitando disputas violentas e facilitando as relações entre ambos. Com a chegada dos franceses comandados por Villegagnon, Anchieta interrompe seu trabalho junto aos índios para negociar a paz. Com Nóbrega, Anchieta dedica-se aos índios tamoios, pondo fim às lutas. A morte de Nóbrega e a decretação da escravidão dos índios abalam o apóstolo. Adoentado, vê morrer a raça por quem tanto lutou. À encenação dos últimos momentos de sua vida, segue-se a consagração do missionário jesuíta, numa figuração alegórica que o coloca como mito fundador da civilização sincrética dos trópicos ${ }^{6}$. Essa é a síntese do filme.

A história conta que José de Anchieta nasceu em Laguna, capital da ilha de Tenerife, arquipélago das Canárias, em 19 de março de 1534, dia de São José. Filho do basco Juan de Anchieta e da canária Mencía Díaz de Clavijo y Llarena, aos 16 anos, José de Anchieta é enviado a Coimbra para cursar a faculdade 
onde estudou Filosofia, Dialética e Letras. "Já escrevia poemas em latim, o que fará a vida inteira. [...]. Enquanto estudante, cheio de fervor, Anchieta um dia fez votos de castidade de joelhos diante da imagem de Nossa Senhora, na Sé de Coimbra"7. Em 1551 passa a estudar na classe em que o padre Antonio Corrêa preparava missionários para os esquadrões avançados encarregados da evangelização na Ásia, África e América ${ }^{8}$. A história também conta que José era um menino de saúde frágil. Fragilidade física que se agravou quando uma escada caiu em suas costas. Esse foi um dos motivos de ter sido enviado ao Brasil. Corria a fama de que os ares e o clima da nova terra eram bons. José de Anchieta desembarcou em São Vicente na véspera do Natal de 1553, junto com outros padres missionários. Em São Vicente, encontra-se com o Padre Manoel da Nóbrega, fundador da catequese no Brasil. Tornam-se amigos. Nóbrega, na época, estava interessado em mudar o colégio de São Vicente para o Planalto. De acordo com Toledo, o lugar já estava escolhido.

Ficava a 10 léguas do mar, como já explicara Nóbrega, e a duas de "uma povoação de João Ramalho". Ali o superior dos jesuítas vinha juntando as tribos esparsas da região, com os quais pretendia fundar a tal sociedade nova, composta de cristãos impecáveis capazes de passar o mundo a limpo. O local era uma elevação, na confluência de dois rios. [...] Já se sabe onde estamos: na elevação a cavaleiro dos rios Tamanduateí e Anhangabaú .

Nesse local, sabemos que foi erguida uma casa para os jesuítas e sede do colégio. Como é sabido que o dia 25 de janeiro foi o dia da conversão de São Paulo. A fundação do colégio e a missa rezada faziam parte do cotidiano dos padres empenhados na catequese dos índios. Só mais tarde, quando houve a necessidade de se estabelecer um marco fundador da cidade é que a data 25 de janeiro de 1554 e a missa celebrada foram transformadas na data da fundação de São Paulo. Piratininga ficou por conta de Anchieta que sempre "terminava suas cartas 'de Piratininga' ou 'de Piratininga, no colégio de São Paulo', ou ainda, 'em Piratininga, em São Paulo da Companhia de Jesus'. [...] Numa carta de 1562, escreve pela primeira vez 'São Paulo de Piratininga" ${ }^{10}$. Piratininga na língua tupi quer dizer "peixe seco", ou "deixado a secar". Embora saibamos que existe uma discussão em torno do nome Piratininga, já conhecida pelos índios como o nome de um lugar, uma região, uma aldeia de índios (outro motivo de discordância entre estudiosos), esses dados históricos nos interessam porque estão presentes na ficção, a demarcação da terra onde seria erguido o colégio, a cruz e a missa rezada com índios em volta dela, e a terra foi nomeada como marco da fundação de São Paulo.

No filme, quando a Companhia de Jesus o envia para o Brasil, o Gover-

7 TOLEDO, Roberto Pompeu. A capital da solidão. Uma história de São Paulo das origens a 1900. Rio de Janeiro: Objetiva, 2012, pp. $96-97$.

8 Idem, p. 97.

9 Idem, p. 98.

10 Idem, p. 101. nador Geral iniciava a tentativa de escravizar os índios. João Ramalho e Diogo Álvares movimentam o mercado escravo nas aldeias e queriam acabar com a catequese. No colégio fundado por Anchieta e Nóbrega são encenados autos que contam um pouco sobre a formação do Brasil. Os dois padres estabelecem uma trégua com os índios tamoios, tentando persuadi-los a favor dos jesuítas. Nóbrega volta para São Vicente a pedido de Anchieta. Em 1570, Nóbrega morre 
no Rio de Janeiro, e Anchieta não aceita ser reitor na Bahia, continuando a defender a Companhia de Jesus e os índios. Anchieta parte para o Espírito Santo, para continuar a doutrinação dos índios e concretizar o sonho de Nóbrega, formando uma comunidade tupi-guarani. Em 1597, velho e enfermo, continua ajudando doentes e índios. Morre e é feita uma procissão com seu corpo, durante a qual Anchieta, santificado, se levanta e observa a festa. Final da vida do jesuíta e do filme de Paulo César Saraceni.

O filme Palavra e utopia (2000), de Manuel de Oliveira, narra a história política e religiosa do Padre Antonio Vieira no Brasil e na Europa. A história começa no ano de 1663. Vieira é convocado a comparecer diante o tribunal da Inquisição portuguesa para explicar as ideias que defende ao questionar a escravidão, a situação dos índios e as relações império-colônia. Intrigas na corte e um pequeno mal-entendido enfraquecem o poder do jesuíta, que chegou a ser amigo íntimo do rei D. João IV. Perante os juízes, Padre Vieira passa a limpo seu passado: a juventude no Brasil e os anos de noviciado na Bahia, seu envolvimento na causa dos índios e o primeiro sucesso no púlpito. Proibido pela Inquisição de falar em público, ele se refugia em Roma, onde conquista enorme reputação e sucesso. A rainha Cristina da Suécia, que vivia em Roma desde sua abdicação, manteve Vieira na Corte e insistiu para que se tornasse o seu confessor. Com saudades de Portugal, o padre retorna a seu país. Entretanto, a frieza com que é recebido pelo novo rei, D. Pedro, força sua volta ao Brasil, onde passou os últimos anos de sua vida ${ }^{11}$.

Antonio Vieira nasceu em Lisboa, no dia 6 de fevereiro de 1608. Na cinebiografia de Vieira, Manoel de Oliveira apresenta cronologicamente a trajetória política e religiosa do padre, tanto no Brasil como na Europa. Desde 1614, quando parte com a família para o Brasil, com destino à Bahia, até 1697, quando morre no colégio da Bahia. Em 1623, entra no noviciado local da Companhia de Jesus e, ainda noviço, aos 18 anos, foi encarregado de escrever a Carta Ânua ao Geral dos Jesuítas historiando os sucessos da ocupação da Bahia pelos holandeses. Em 1633, estreia no púlpito, para o público, na Igreja da Conceição, na Bahia. Recuperada a cidade, em 1634 ordena-se sacerdote e celebra sua primeira missa. Em seus primeiros votos religiosos, "logo inseriu-se resolutamente o de se consagrar ao serviço dos índios e dos negros, para o que passara a estudar a língua brasílica e a de Angola"12. Estuda Filosofia e Teologia, organiza compêndios dessas matérias para seu uso nos colégios da Companhia de Jesus em Olinda e Bahia. Nas palavras de Eugênio Gomes:

Não era a cátedra, porém, o que o interessava, senão a tarefa ousada e áspera do desbravamento das tribos selvagens, desafiando mil e uma peripécias sertão adentro. Após completar os estudos, percorrendo por cinco anos as aldeias de índios da Bahia e pregando aos bugres em sua própria e bárbara língua ${ }^{13}$.

Esse período retrata a primeira parte da vida de Vieira e do filme de Oliveira. Em 1638, novamente enfrenta os contratempos da guerra de invasão prestando serviços no cerco da Bahia. A segunda parte do filme ocorre exatamente no

11 Cinemateca de São Paulo.

12 GOMES, Eugênio. Apresentação. In: Vieira, Antonio. Sermões. Rio de Janeiro: Agir, 1988, p. 9. 13 Idem, ibidem. 
momento em que Vieira, com saudades de sua terra natal, em 1641, embarca para Portugal integrando uma embaixada junto a D. João IV. Em 1642, estreia na Capela Real, em Lisboa, com o Sermão dos Bons Anos. Em 1644, torna-se Pregador Real e Tribuno da Restauração. Em 22 de novembro de 1652, embarca para o Brasil a fim de iniciar a Missão no Maranhão. Em 1654, embarca novamente para Portugal. Em 1655, obtida a Lei da Liberdade dos Índios, retorna ao Maranhão. No Maranhão, apesar do apoio inicial dado por D. João IV a Vieira, "os padres não puderam executar livremente o seu plano de aldeamentos no sertão, pois o capitão-mor ordenou que se restringissem 'ao ensino de Doutrina e Latim', avocando para si a questão do trabalho indígena"14. Em 1661, juntamente com outros jesuítas é expulso do Maranhão, chegando em novembro a Lisboa. Em 1662, com a revolução palaciana, Vieira é desterrado para o Porto. Em 1665, é preso pela Inquisição e mantido sob custódia em Coimbra. Em 1667, o Santo Ofício lhe cassa a palavra e submete-o à reclusão. Absolvido no ano de 1668. Entre 1668 e 1675, Vieira se refugia em Roma. Fim da segunda parte da história de Vieira. Em 1681, parte para a Bahia e vai residir na Quinta do Tanque, arrabalde da cidade, onde passa a organizar as suas obras para publicação. Ainda entre os anos de 1683 e 1688, enfrenta sérios problemas de ordem política: é envolvido injustamente na morte do Alcaide da Bahia, e em 1688, é nomeado Visitador-Geral do Brasil, sem poder sair da Bahia. Em 1697, cego e muito doente, morre no Colégio da Bahia. Essa é a terceira parte do filme, Vieira velho. Essa fase da vida de Antonio Vieira é interpretada por Lima Duarte.

\section{NAS IMAGENS FÍLMICAS, A FORÇA DA PALAVRA E A AMBIGUIDADE DOS AFETOS}

Cem anos separam a vida e a morte dos padres Anchieta (1597) e Vieira (1697). Nos quase cem anos de colonização portuguesa antes da vinda de Vieira para o Brasil, os contatos, a aculturação dos índios, a escravidão e o início de seu apagamento como sujeito histórico já estavam avançados. Apesar de a trajetória religiosa e política de cada um ter sido diferente, um ponto é comum aos dois padres: eram letrados e sabiam que no domínio da língua nativa estava a certeza da dominação de sua cultura e de sua história, fossem os índios do litoral, como fez Anchieta, fossem os do sertão, como quis Vieira. Sob o manto sagrado da Igreja Católica, em nome da conversão do gentio, o caminho para que esses dois objetivos se realizassem foi a catequese. Não a simples pregação, mas o uso refinado da retórica e a construção de um discurso ambíguo que pregava a liberdade e a salvação, mas que tinha na sua prática a rigidez dos códigos de conduta e o autoritarismo. A palavra falada tinha uma força muito especial, fosse por meio da poesia, das peças teatrais, como fez Anchieta, fosse pelos sermões ditos do púlpito por Vieira. Para os dois, lugares eram teatros,

14 BOSI, Alfredo. Dialética da colonização. São Paulo: Companhia das Letras, 1992, p. 137. portanto, locais de encenação, de representação. O cinema é um meio privilegiado porque consegue partir das palavras e criar as imagens andantes, ou mostrar pelas imagens as palavras em movimento. 
O filme Anchieta, José do Brasil, depois de apresentar rapidamente a vida do padre menino em Tenerife, sua ida para Coimbra e a consagração dos votos de castidade frente à imagem de Nossa Senhora; de mostrar o jovem padre envolvido com suas poesias, sua saúde precária até a resolução de seus superiores de que ele seria incorporado ao esquadrão avançado de evangelização nas colônias portuguesas, ordena que ele venha para o Brasil, mostra a chegada de Anchieta desembarcando na Bahia junto com o governador Duarte da Costa. Na praia, colonos e índios naturalmente convivendo. Assim que o padre sai do barco, os índios o rodeiam e alisam a cruz que ele traz no peito. Em outra sequência uma missa é rezada e todos participam, colonos e índios, até o momento em que o governador invade uma aldeia. A voz de Anchieta narra a invasão, o incêndio, o massacre e diz: "os indios brasileiros não se deixam escravizar, são corajosos e destemidos preferindo a morte à escravidão. Mas a cobiça dos conquistadores exige mais energia, o governo começa a agir". Anchieta, aos pés da cruz, ergue uma criança e a batiza com o nome de Brasil. Anchieta anda pela mata, fala sobre o canibalismo e da importância de tornar os índios cristãos. Em seguida, parte para São Vicente, onde o padre Manuel da Nóbrega o espera. Em conversas com Nóbrega, explicitam por que estão no Brasil: "viemos à conversão do Brasil, fazer um país". Nóbrega quer ir até o Paraguai. Anchieta diz: "é em obediência em Deus que devemos aprender a língua deles, a língua dos índios. Serão eles que ensinarão os nossos caminhos. O Brasil é deles e para eles". Nóbrega fala: "fundaremos um colégio o de Piratininga, que será a nossa ponte entre eles e João Ramalho e Tibiriçá". Em uma de suas cartas Anchieta diz que aprendeu muito com os índios e em apenas três meses aprendeu a língua dos índios e que estava a escrever uma gramática da língua mais falada das costas do Brasil. Escreve: "os indios são dóceis e amáveis para quem os trata como iguais. Desde os mais mocos ajudam com os instrumentos musicais, entoam cantigas que compus para eles em tupi e português. As indias são muito religiosas e aprendem a rezar com muita facilidade, os filhos dos portugueses se misturam aos curumins, uma troca amorosa". Nesses trechos podemos ter uma ideia do processo de aculturação linguística. A fundação do colégio e a construção de uma gramática para a realização da catequese teriam os corpos e as almas disciplinados pelo poder da palavra. Alfredo Bosi ${ }^{15}$ (1992), ao analisar a produção poética de Anchieta explica que quando Anchieta, escrevia para os nativos, ou para os colonos que já entendiam a língua geral da costa, escrevia sempre em tupi. E que o

trabalho de aculturação linguística é, nesses textos, a marca profunda de uma situação historicamente original. O poeta procura, no interior dos códigos tupi, moldar uma forma poética bastante próxima das medidas trovadorescas em suas variantes populares ibéricas: como o verso redondilho forja quadras e quintilha nas quais se arma um jogo de rimas ora alternadas, ora opostas. [...] Jandé, rebuté, Iesu, Jandé rekobé meengára, oimomboreausukatú, Jandéamotareymbára. Jesus, nosso verdadeiro Pai, senhor da nossa existência, aniquilou nosso inimigo ${ }^{16}$.

Esse exemplo é dado para entendermos por que "aculturar também é sinônimo de traduzir". Diz Bosi: "as palavras são tupis (com exceção de Iesu), tupi é a sintaxe, mas o ritmo do período, com seus acentos e pausas, não é indígena, é português"17. E também para explicar o quanto o "projeto católico de transpor

15 Idem. 16 Idem, p. 64. 
para a fala do índio a mensagem católica demandava um esforço de penetrar no imaginário do outro, e este foi o empenho do primeiro apóstolo". Segundo Bosi: "na passagem de uma esfera simbólica para outra Anchieta encontrou óbices por vezes incontornáveis. Como dizer aos tupis, por exemplo, a palavra pecado se eles careciam até mesmo de sua noção [...]". A aculturação católico-tupi foi pontuada de soluções estranhas, quando não violentas. Como nos interessa mostrar o processo de dominação e apagamento da cultura indígena, vale conhecer outro exemplo dado por Bosi. O exemplo é sobre o círculo sagrado dos indígenas.

O círculo sagrado dos indígenas perde a unidade fortemente articulada que mantinha no estado tribal e reparte-se, sob a ação da catequese, em zonas opostas e inconciliáveis. De um lado, o Mal, o reino de Anhanga, que assume o estatuto de um ameaçador Anti-Deus, tal qual o Demônio hipertrofiado das fantasias medievais. De outro lado, o Bem, onde Tupã se investe de virtudes criadoras e salvíficas, em aberta contradição com o mito original que lhe atribuía precisamente os poderes aniquiladores do raio ${ }^{18}$.

Esse maniqueísmo foi largamente usado por Anchieta em suas peças teatrais. O mundo separado em duas forças em intermináveis lutas: "Tupã-Deus, em sua constelação familiar de anjos e santos, e Anhanga-Demônio, com sua coorte de espíritos malévolos que se fazem presentes nas cerimônias tupis"19. Anchieta, para atrair os colonos e os índios, costumava fazer da praça que ficava em frente ao Colégio um palco onde encenava os autos escritos em tupi, português, espanhol e latim. No filme é representado o Auto da Pregação, em que todos os personagens falam do arrependimento. Quando Anchieta diz que está a escrever uma gramática da língua mais falada das costas do Brasil, podemos nos reportar aos estudos de Eni Orlandi ${ }^{20}$ e trazer suas reflexões sobre a real intenção dos missionários quanto ao aprendizado da língua. Para Eni Orlandi, "os missionários estudaram e estudam a língua com finalidades utilitárias de evangelização. [...] Disciplinaram o tupi, instituindo o tupi jesuítico, a fim de instalar o seu poder de controle sobre os índios e o seu poder de negociação com o governo português" ${ }^{21}$. Continua a autora, "quando os missionários falavam a língua do índio ou quando falavam dos índios, não falavam com eles nem os tomavam como interlocutores reais. $\mathrm{O}$ destinatário efetivo era o governo português [...] Pela disciplinarização da língua indígena, pretende-se 'saber' a língua, mas se está sobretudo modificando-a no sentido dos modelos ocidentais (europeu)"22. Basta recuperarmos o exemplo dado

17 Idem, p. 65.

18 Idem, p. 66.

19 Idem, p. 68.

20 ORLANDI, Eni Puccinelli. Terra à vista! Discurso do confronto: velho e novo mundo. Campinas: Editora da Unicamp, 2008.

21 Idem, p. 87.

22 Idem, p. 88.

23 BOSI, op. cit., p. 93. por Bosi sobre os poemas de Anchieta escritos e falados em tupi. Esses exemplos são ínfimos perto da complexidade da temática, e só foram trazidos para mostrar como as relações entre o colonizador e o colonizado são ambíguas. Para justificar, trago uma vez mais um trecho da análise de Bosi sobre o Padre Anchieta.

O fato de ter vivido inspirado pela sua inegável boa-fé de apóstolo apenas torna mais dramática a constatação desta quase-fatalidade que divide o letrado colonizador em um código para uso próprio (ou de seus pares) e um código para o uso do povo. Lá o símbolo e a efusão da subjetividade; aqui o didatismo alegórico rígido, autoritário. Lá a mística da devotio moderna; aqui, a moral do terror das missões ${ }^{23}$. 
Contradições, contrastes, ambiguidades vividas pelos intelectuais que moravam na colônia. Com Antonio Vieira não foi diferente, como podemos ver no filme e em sua trajetória de vida.

A trajetória religiosa e política de Vieira encheu quase todo o século XVII, na sua maior parte neste país, que considerava a sua segunda pátria, escreveu Eugênio Gomes (1988) nos estudos críticos que fez sobre Antonio Vieira. Conselheiro de reis, confessor de rainhas, preceptor de príncipes, diplomata em cortes europeias, defensor de cristãos-novos e com igual zelo missionário no Maranhão e no Pará, para os indígenas Vieira era "Paiaçu" (Padre Grande ou Pajé-Grande). Embora o filme apresente o padre na sua juventude convencendo seus colegas sobre a necessidade de aprender a língua dos índios, são poucos os momentos em que a presença do índio é marcante na ação. Apenas no momento em que os holandeses invadem o colégio, roubam e agridem o padre, os índios armados com flechas fazem uma figuração no filme defendendo o colégio e os padres, ou, quando Vieira prega para negros, colonos e índios, a igualdade entre os homens, afinal, diz: "E entre cristão e cristão não há diferença de nobreza, nem diferença de cor. Não há diferença de nobreza porque todos são filhos de Deus; nem há diferença de cor porque todos são brancos". A brancura de todos se deu pelo batismo. Depois dessas sequências, o índio só aparece nos discursos ou nos sermões, como no Sermão da Epifania, pregado na Capela Real, em 1662, perante a rainha viúva dona Luísa, que regeu os negócios da monarquia durante a minoridade de D. Afonso VI, como vimos anteriormente. Esse Sermão foi pronunciado quando ele e outros missionários estavam retornando a Lisboa expulsos pelos colonos após uma série de atritos causados pela questão do cativeiro. "O pregador, valendo-se da presença da regente e do menino, futuro rei, pede que os jesuítas voltem ao Maranhão e possam implantar missões autônomas em relação aos senhores de escravos" ${ }^{24}$. O Sermão é considerado exemplar pelos estudiosos de Vieira por apresentar abertamente os conflitos sociais, "os interesses em jogo, obrigando o discurso ora avançar até posições extremas, ora a compor uma linguagem de compromisso" ${ }^{25}$. O púlpito sagrado era o palco para Vieira, era o local onde se colocava em situação de combate, de defesa ou ataque. Local onde mostrava a força da palavra e a dimensão que a retórica podia alcançar. Utilizando-se do método parenético, transformando ideias em argumento teológico, "engenhoso processo de acomodação analógica entre um ou mais episódios do Velho ou do Novo Testamento e determinado acontecimento histórico, que o pregador tomava a si explicar ou interpretar por esse meio" ${ }^{26}$, Vieira transforma esse processo acomodatício entre o sagrado e o particular em recurso estratégico para expor seus pensamentos e convencer, fazer vibrar ou intimidar o público para o qual se dirigia.

Sequências de pregações tão bem compostas e mostradas no filme de Manuel de Oliveira que podemos acompanhar e entender, mesmo que através dos fragmentos de Sermões, por que Fernando Pessoa nomeou Vieira de "imperador da língua portuguesa”, e por que, por exemplo, o Sermão da Sexagésima (1655) é considerado o resumo de seu método e a verdadeira arte de pregar.

24 Idem, p. 134. 25 Idem, ibidem. 26 GOMES, op. cit., p. 11 
Mas nos Sermões estão também as contradições do pregador. Se a atividade do missionário foi a que exerceu com devotamento, enfrentando ao mesmo tempo o trabalho de catequese e a agressividade dos colonos portugueses sobre os índios, também é verdade que o compromisso político com esses mesmos colonos, de "descer com os portugueses ao sertão, domesticar e reduzir os aborígines à obediência; enfim, trazê-los a Belém do Pará e a São Luís para trabalharem metade do ano nas roças dos colonos" ${ }^{27}$, mostrava as contradições da Igreja e e as de Vieira como missionário.

Se o filme mostra um Vieira que desde as primeiras pregações em público tratava dos problemas sociais dos negros, condenando de maneira inapelável o aviltamento da condição humana, também deixa transparecer no seu discurso, "o princípio estabelecido do cativeiro justo" ${ }^{2}$. Para mostrar a consciência que Antonio Vieira tinha sobre as contradições da Igreja Católica e as suas, cabe abordar a proposta conciliatória de Vieira aos colonos do Maranhão. Na proposta, Vieira explica aos colonos os três tipos de índios existentes no Maranhão: os escravos que já estão na cidade; os que vivem nas aldeias de el-rei como livres, e os que moram nos sertões. Os escravos da cidade que serviam diretamente aos colonos. Como já tinham sido herdados ou havidos de má-fé, podiam ter o direito de escolher entre sair do cativeiro ou continuar nos trabalhos que faziam. A proposta, no caso, é oferecer-lhes a liberdade de ir para "as aldeias de El-Rei”, que são missões jesuítas apoiadas moralmente pela Coroa. Os escravos das aldeias de el-rei. Nada havia a propor porque já eram livres, de acordo com Vieira. E, por último, os que vivem nos sertões. Destes só poderiam ser tirados aqueles que já estivessem cativos de tribos inimigas e na iminência de serem mortos. Os colonos os libertariam trazendo-os à cidade como escravos. É o que se chamava de "operação resgate", pela qual os portugueses levavam consigo os condenados, os "índios de corda" ${ }^{29}$. Imagem trazida por Saraceni na primeira parte da vida de Anchieta, índios amarrados em corda, apenas para lembrar.

As contradições e ambiguidades estão enraizadas desde as origens. Antonio Vieira, apesar de dizer que o Brasil era sua segunda pátria e lutar em favor dos indígenas da Província do Brasil, era antes de tudo missionário devoto da Companhia de Jesus e do Reino de Portugal. E aqui concordo com Bosi quando diz:

O interesse que ainda hoje desperta a sua obra extensa e vária (207 sermões, textos exegéticos, profecia, cartas, relatórios políticos...) só tem a ganhar se for norteado por um empenho interpretativo que consiga extrair dela a riqueza das suas contradições, que são as do sistema colonial como um todo, e que só a experiência brasileira, de per si, não explica ${ }^{30}$.

E se precisamos, como nos diz Bosi, considerar o óbvio e lembrar que a

27 BOSI, op. cit., p. 136.

28 GOMES, op. cit., p. 15.

29 BOSI, op. cit., p. 139

30 Idem, p. 119. acão de Vieira se deu em pleno antigo regime, antes que a crítica das Luzes começasse a arranhar a metafísica social incrustada nos estamentos, creio que é necessário considerar o óbvio de que o cinema é também uma representação, que mesmo tendo nos chamados documentos históricos e literários a base para a construção de seus argumentos, ele é ficção e construção de um olhar sobre 
Entre palavras e imagens. Onde fica mesmo o índio na fundação do Brasil? •

Maria Ignês Carlos Magno

o objeto escolhido. E porque a ficção permite que cada um tenha sobre ela uma leitura, considero interessante discutir os filmes nesta ótica: a da força da palavra e da ambiguidade contidas nos discursos, nos afetos e nas relações do Padre Anchieta e do Padre Vieira com o Brasil e com os índios do Brasil.

\section{REFERÊNCIAS}

ANCHIETA, JOSÉ DO BRASIL. Direção: Paulo César Saraceni. Gênero: drama. Argumento e roteiro: Marcos Konder Reis e Paulo César Saraceni. Fotografia: Marco Bottino. Fotografia de cena:José Reinaldo Lutti. Montagem: Ricardo Miranda. Música: Sérgio Guilherme Saraceni. Arranjos: Luiz Roberto Oliveira. 1977.

BOSI, Alfredo. Dialética da colonização. São Paulo: Companhia das Letras, 1992.

GOMES, Eugênio. Apresentação. In: Vieira, Antonio. Sermões. Rio de Janeiro: Agir, 1988.

JESUS, Samuel de. Saudade. Da poesia medieval à fotografia contemporânea, o percurso de um sentimento ambíguo. Belo Horizonte: Autêntica Editora, 2015.

ORLANDI, Eni Puccinelli. Terra à vista! Discurso do confronto: velho e novo mundo. Campinas: Editora da Unicamp, 2008.

PALAVRA E UTOPIA. Direção: Manoel de Oliveira. Gênero: drama. Argumento e roteiro: Manoel de Oliveira. Montagem: Valérie Loiseleux. 2000.

TOLEDO, Roberto Pompeu. A capital da solidão. Uma história de São Paulo das origens a 1900. Rio de Janeiro: Objetiva, 2012. 